University of Wollongong

Research Online

Faculty of Engineering - Papers (Archive)

Faculty of Engineering and Information

Sciences

April 1998

\title{
Method to estimate water storage capacity of capillary barriers
}

J. C. Stormont

University of New Mexico, USA

C. E. Morris

University of Wollongong

Follow this and additional works at: https://ro.uow.edu.au/engpapers

Part of the Engineering Commons

https://ro.uow.edu.au/engpapers/208

\section{Recommended Citation}

Stormont, J. C. and Morris, C. E.: Method to estimate water storage capacity of capillary barriers 1998. https://ro.uow.edu.au/engpapers/208 


\title{
Method to Estimate Water Storage Capacity of Capillary Barriers
}

\author{
By John C. Stormont ${ }^{1}$ and Carl E. Morris, ${ }^{2}$ Members, ASCE
}

\begin{abstract}
This paper presents a method to estimate the additional storage capacity derived from the presence of a capillary break or barrier beneath a soil layer used in a surface cover system. The method involves first estimating the suction head profile in the soil layer at breakthrough. Then, using a relationship between suction head and water content (i.e., the moisture characteristic function), the corresponding water content profile is derived. Integrating the water content over the depth of the soil layer yields the total water in the layer from which the net storage capacity can be determined. Good agreement was obtained between the water storage capacity calculated using this method to those derived from numerical simulations. Example calculations illustrate the influence of the overlying soil texture, thickness, and the water entry head of the coarse layer on the storage capacity of a capillary barrier system. The paper also discusses how the moisture characteristic curve provides insight into the expected storage capacity for a soil in a capillary barrier configuration.
\end{abstract}

\section{INTRODUCTION}

A component of essentially all surface cover systems is a soil layer intended to store some portion of the precipitation that falls on the site. The soil layer often also serves as a rooting medium for surface vegetation. Water stored in this layer can be removed by evaporation and/or transpiration (collectively referred as evapotranspiration, ET), drain laterally out of the cover system, or migrate downward into lower portions of the cover system or into the underlying waste.

For dry climates, a cover system comprised only of a soil layer designed to store water and support surface vegetation may be sufficient to limit net percolation through the cover system to acceptable levels. The strategy with these simple soil covers is to ensure that the storage capacity of the soil is sufficient to store the probable precipitation until it is removed by evapotranspiration. The maximum water content a soil can hold before it drains downward is approximated as its field capacity (FC), which is the water content after free or gravity drainage. Field capacity is often arbitrarily reported as the water content at about $3,500 \mathrm{~mm}$ of suction head (Jury et al. 1991). Below field capacity, the hydraulic conductivity is often assumed to be so low that gravity drainage becomes negligible and the soil moisture is held in place by suction. The storage capacity (SC) of a soil layer can be determined by integrating its volumetric water content $(\theta)$ over its thickness $(b)$. Assuming a constant field capacity, the water storage capacity for a simple soil cover can be described by

$$
\mathrm{SC}=\int_{0}^{b} \theta d z=(\mathrm{FC}) b
$$

However, not all of this stored water can be removed by plants. Vegetation can reduce the soil moisture content to the permanent wilting point (PWP), which is typically defined as the water content at $150 \mathrm{~m}$ of suction head (Cassel and Nielsen 1986). Evaporation from the soil surface can further reduce the soil moisture below the wilting point down to the residual saturation, which is the water content at an infinite suction. If water is only removed by plants (a reasonable assumption

\footnotetext{
'Assoc. Prof., Dept. of Civ. Engrg., Univ. of New Mexico, Albuquerque, NM 87131; E-mail jestorm@unm.edu.

${ }^{2}$ Lect., Dept. of Civ. and Mining Engrg., Univ. of Wollongong, Wollongong, NSW 2522, Australia; E-mail rmorris@uow.edu.au.

Note. Discussion open until September 1,1998 . To extend the closing date one month, a written request must be filed with the ASCE Manager of Journals. The manuscript for this paper was submitted for review and possible publication on May 12, 1997. This paper is part of the Journal of Geotechnical and Geoenvironmental Engineering, Vol. 124, No. 4, April, 1998. OASCE, ISSN 1090-0241/98/0004-0297-0302/\$4.00 + $\$ .50$ per page. Paper No. 15758 .
}

since evaporation is usually described as a surface process), the net storage capacity (NSC), also called the available water capacity, of a soil layer can be approximated by

$$
\text { NSC }=(\text { FC }- \text { PWP }) b
$$

In many dry climates, plants will reduce the water content of a near-surface soil to the PWP every growing season (Anderson et al. 1993; Gee et al. 1994), making the entire NSC available to store subsequent precipitation when ET is low and the plants are dormant. Thus, if the net storage capacity exceeds the precipitation during dormant periods, there will be no net percolation through the cover. Design of such a system essentially requires determining the thickness of the soil layer required to provide the desired storage capacity and specifying the appropriate surface vegetation (Anderson et al. 1993). However, if soil layer thickness is much greater than the rooting depth of the vegetation, it will be difficult for the moisture that moves past the rooting depth to be drawn upward and removed.

The placement of a capillary break or barrier within a soil layer has been suggested as a means of preventing downward water movement (Johnson et al. 1983; Hakonson et al. 1989), essentially increasing the storage capacity of the overlying soil layer. The capillary barrier can be formed by placing a relatively coarse-grained soil such as a coarse sand or gravel beneath the relatively fine-grained soil layer. In a capillary barrier configuration, the water content of the overlying fine soil layer is increased above that associated with free downward drainage and thus its water storage capacity is increased. However, there is no simple method to estimate the increased storage capacity afforded by the capillary barrier, hampering efforts to advance the use of capillary barriers from experimentation to practice. The purpose of this paper is to propose a method to estimate the storage capacity of a capillary barrier cover system. The method involves first estimating the suction head profile in the overlying soil layer at breakthrough, defined as when water first moves into the coarse layer. Then, using a relationship between suction head and water content (i.e., the moisture characteristic function), the corresponding water content profile is derived. Integrating the water content over the depth of the overlying soil layer yields the total water in the layer, from which the net storage capacity can be determined.

\section{SOIL SUCTION HEADS IN LAYER ABOVE CAPILLARY BREAK}

The suction heads in the soil above a capillary break at breakthrough depend on the infiltration rate (fiux) of water into the soil. This can be most clearly envisioned for the case of a constant flux into a soil that is at equilibrium under dry con- 


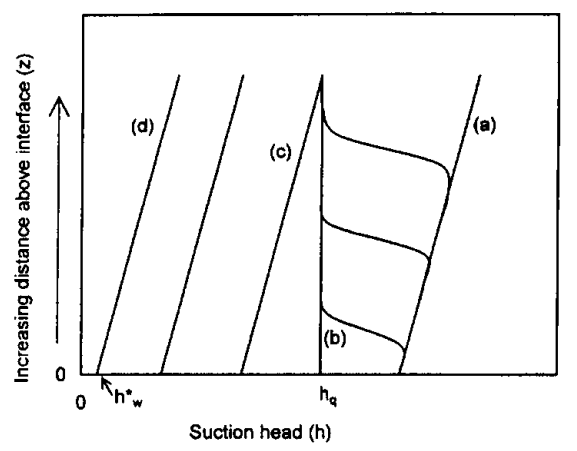

FIG. 1. Suction Heads in Soil Layer above Capillary Barrier in Response to Relatively Slow Constant Infiltration

ditions, i.e., at high initial suction heads. First consider the case of a relatively slow constant flux (Fig. 1). The wetting front moves through the soil, decreasing the initial equilibrium suction heads [Fig. 1(a)] to a nearly uniform value of $h_{q}$ [Fig. 1(b)]. The decreased suction head increases the hydraulic conductivity, $K$, sufficiently for the soil to accept the flux, $q$; that is,

$$
K\left(h_{q}\right)=q
$$

where $K\left(h_{q}\right)=$ hydraulic conductivity at suction head $h_{q}$. When the wetting front reaches the interface, the coarse layer serves as a barrier if $h_{q}$ is greater than the water entry head of the coarse layer, $h_{w}^{*}$. The water entry head is the suction head at which the initially dry coarse layer will first admit water (Baker and Hillel 1990). The water entry head has been measured for sands and gravels when these materials have been used as the coarse layer in a fine-over-coarse configuration (Baker and Hillel 1990; Stormont 1997). The suction head near the fine-coarse interface is monitored during infiltration into the fine layer, and the suction head at breakthrough of water into the coarse layer is taken as the water entry head. The more coarse and uniform a soil is, the lower and more distinct the water entry head is. For example, a uniform pea gravel (with nominal $10 \mathrm{~mm}$ particle size) has a water entry head of about $20 \mathrm{~mm}$, whereas a poorly graded concrete sand has a water entry head in the range of 300 to $400 \mathrm{~mm}$ (Stormont 1997). Baker and Hillel (1990) have suggested that the water entry head can be approximated as the height of capillary rise within a soil and can be estimated from the inflection point in the moisture characteristic curve.

If a barrier is formed by the underlying coarse layer, infiltrating water will distribute itself within the overlying soil, decreasing the suction heads throughout the overlying soil layer. In response to the slow infiltration, the total head gradient in the overlying soil will be very small. The suction heads in the overlying soil, in turn, will tend toward a "unit slope profile", [Fig. 1(c)]:

$$
\frac{d h}{d z}=1
$$

where $z=$ elevation above the interface. During slow constant infiltration, the suction head profile will approach but not fully achieve a unit slope as downward flow requires a nonzero total head gradient, however small. The deviation of the suction head profile from the unit slope depends upon the infiltration rate and the soil properties, and will be discussed further in this paper.

Ongoing infiltration into the overlying soil at a slow rate will continually shift all of the suction heads to lower values while preserving a suction head profile near the unit slope. Eventually, the suction head at the interface approaches $h_{w}^{*}$, and the capillary barrier fails [Fig. 1(d)], i.e., water flows into the coarse underlying soil. The unit slope suction head profile within the overlying fine soil layer at breakthrough is given by

$$
h=z+h_{w}^{*}
$$

The suction head profile response to a relatively fast infiltration rate will be different than that discussed previously. In particular, a unit slope will not be approached in the overlying soil if the constant infiltration flux is greater than a critical flux $\left(q_{c}\right)$, which is given by

$$
q_{c}=K\left(b+h_{w}^{*}\right)
$$

where $K\left(b+h_{w}^{*}\right)=$ hydraulic conductivity at suction head $b$ $+h_{w}^{*}$; and $b=$ total height of the fine soil above the interface. During the initial wetting from equilibrium [Fig. 2(a)], the soil will assume the suction head $\left(h_{q}\right)$ necessary to transmit the imposed flux. Once the wetting front reaches the interface [Fig. 2(b)], the portion of the soil near the interface gets wetter and the suction heads decrease. At breakthrough, the suction heads will follow the unit slope profile from the interface to the height where it intersects the suction head required to accept the flux [Fig. 2(c)].

The suction head profile in a near-surface soil will of course not be as simple as it is for the case of constant rate infiltration. Precipitation will wet the soil layer with pulses of infiltration, while climate-dependent ET will remove water from the system. Consider a capillary barrier system initially at equilibrium, that is, with a unit slope suction head profile within the overlying fine soil layer [Fig. 3(a)]. Evapotranspiration will remove water from the soil layer, with the greatest removal at the surface. This will tend to create upward flow gradients within the soil layer [Fig. 3(b)] that must be overcome in order for water to move downward. Infiltrating water will have to first decrease the suction heads enough to create a downward gradient so that downward flow can occur [Fig. 3(c)]. If the amount of water associated with a pulse of infiltration combined with the antecedent water content is less than the storage capacity of the soil layer, then the barrier will not fail. The

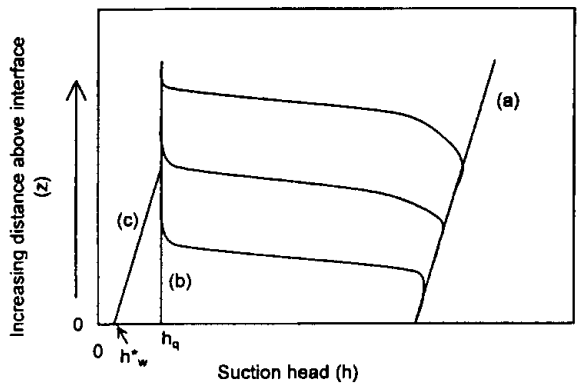

FIG. 2. Suction Heads in Soil Layer above Capillary Barrier in Response to Relatively Fast Constant Infiltration

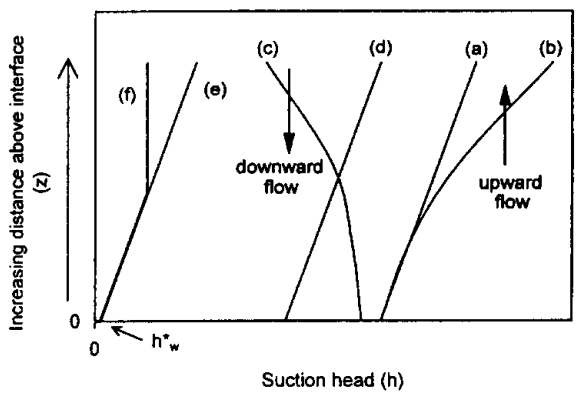

FIG. 3. Suction Heads in Soil Layer above Caplliary Barrier in Response to ET and Pulses of Infiltration 
infiltrating water will be distributed within the fine soil layer to reestablish equilibrium along with a unit slope suction head profile [Fig. 3(d)]. Evapotranspiration will tend to dry out the upper portions of the soil layer in between pulses of infiltration, and the unit slope may be replaced with a profile with greater suction heads near the soil surface [with a shape similar to Fig. 3(b)]. Subsequent pulses of infiltration will make the soil layer progressively wetter, and the unit slope suction head profile that results after each event is moved toward smaller values (to the left in Fig. 3). At some point, an infiltration pulse may exceed the storage capacity of the fine soil layer. If the flux from the pulse is relatively slow $\left(q<q_{c}\right)$, a unit slope suction head profile at breakthrough is expected [Fig. 3(e), similar to Fig. 1(d)]. If the flux is fast $\left(q>q_{c}\right)$, the suction head profile would be similar to the case of constant rate infiltration at a flux exceeding the critical flux [Fig. 3(f), similar to Fig. 2(c)].

\section{Numerical Simulations}

The preceding discussion suggests that the suction head profile at failure in a soil layer overlying a capillary break is expected to resemble that for the case of constant infiltration. To confirm this behavior, numerical simulations were conducted of capillary barriers using daily varying climate as input. The simulations utilized a modeling approach that accounts for near-surface, climate-dependent processes as well as transient, unsaturated flow (Morris and Stormont 1997a). This numerical approach has been demonstrated to satisfactorily simulate unsaturated water movement associated with capillary barriers, including reasonably reproducing field tests (Morris and Stormont 1997b).

Simulations were conducted for a 10-year period using the climate of Chicago. The capillary barrier consisted of $0.66 \mathrm{~m}$ of a silty sand over a gravel with a water entry head of about $100 \mathrm{~mm}$. Details of the simulations including material properties are given in Appendix I. Simulations were conducted with a saturated hydraulic conductivity of the silty sand of 1.4 $\times 10^{-2}$ and $1.4 \times 10^{-3} \mathrm{~mm} / \mathrm{sec}$. In both simulations, the simulated capillary barrier failed three times during the first half of the fourth year in response to successive large precipitation events during the late spring. The time and duration of the breakthrough events was different for the three simulations. In Fig. 4, suction head profiles for each breakthrough event are shown. In every case, the suction head profile at breakthrough was at least as steep as the unit slope as would be expected. The greater the hydraulic conductivity of the soil, the closer the profile is to the unit slope. This is because the critical flux $[(6)]$ is greater and less likely to be exceeded by the infiltration events that fail the capillary barrier.

The numerical simulations confirm that the expected soil suction head profile at failure in response to a daily varying climate will be similar to that for constant infiltration. Because water content monotonically decreases with suction head, the

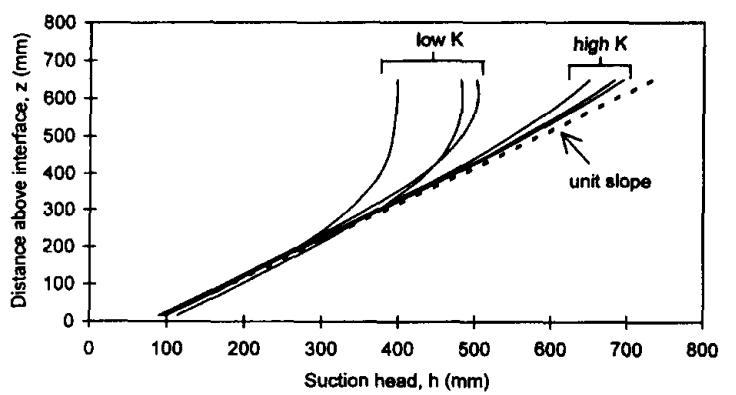

FIG. 4. Simulated Suction Heads in Soll Layer above Capillary Barrier at Breakthrough water content associated with the unit slope suction head profile will always be less than for other suction head profiles at failure. Thus, a lower bound of the water storage capacity of a capillary barrier can be derived from the unit slope suction head profile.

\section{SOIL WATER CONTENTS IN LAYER ABOVE CAPILLARY BREAK}

The water content profile within the overlying soil layer can be determined from the suction head profile using a moisture characteristic function that relates the water content $\theta$ to the suction head, i.e.

$$
\theta=\theta(h)
$$

where $\theta(h)=$ volumetric water content at suction head $h$. The total water can then be found by integrating the soil water content over the height of the soil layer. At breakthrough, assuming the unit slope suction head profile, the storage capacity is given by

$$
\mathrm{SC}=\int_{0}^{b} \theta\left(z+h_{w}^{*}\right) d z
$$

For simple moisture characteristic functions such as that given by Brooks and Corey (1964), the solution to this integral can be found and yields a closed-form expression for the total water content in the overlying soil layer at breakthrough. Other moisture characteristic functions, however, can only be integrated numerically. Consider the widely used function of van Genuchten (1980):

$$
\theta=\theta_{r}+\left(\theta_{s}-\theta_{r}\right)\left[1+(\alpha h)^{n}\right]^{-m}
$$

where the subscripts $s$ and $r$ indicate the saturated and residual values of the water content; $\alpha, m$, and $n$ are fitting parameters; and $m=1-1 / n$. Substituting this expression into (8) yields

$$
\mathrm{SC}=\theta_{r} b+\left(\theta_{s}-\theta_{r}\right) \int_{0}^{b}\left(\left(1+\left[\alpha\left(z+h_{w}^{*}\right)\right]^{n}\right\}^{-m}\right) d z
$$

which can be readily evaluated using a variety of numerical methods.

\section{WATER STORAGE CAPACITY OF CAPILLARY BARRIERS}

The water storage capacity of a capillary barrier calculated using (10) compares well with that derived from numerical simulations. For the soil properties and thickness of the overlying fine soil layer used in the simulations (Appendix I), the estimated water storage capacity of the capillary barrier using (10) is $253 \mathrm{~mm}$. The numerically predicted water in the overlying fine soil layer when water first moved into the underlying coarse layer ranged from 254 to $271 \mathrm{~mm}$. The simulations with the lower hydraulic conductivity result in more water storage within the capillary barrier because the suction head profile deviates the most from the unit slope (Fig. 4). Even so, the maximum storage capacity from the simulations was only about $7 \%$ greater than that predicted using (10). These results indicate that the method presented here based on an assumed unit slope suction head profile provides an effective means for preliminary design of a capillary barrier.

The net storage capacity of a capillary barrier and a gravitydrained layer (i.e., a simple soil cover) are compared for a range of soil textures in Fig. 5. The storage capacity of the capillary barrier is calculated from (10), assuming a 1 -m-thick soil layer overlying a coarse material that has a water entry head of $20 \mathrm{~mm}$, which corresponds to a very uniform, coarse soil such as pea gravel (Stormont 1997). The storage capacity 


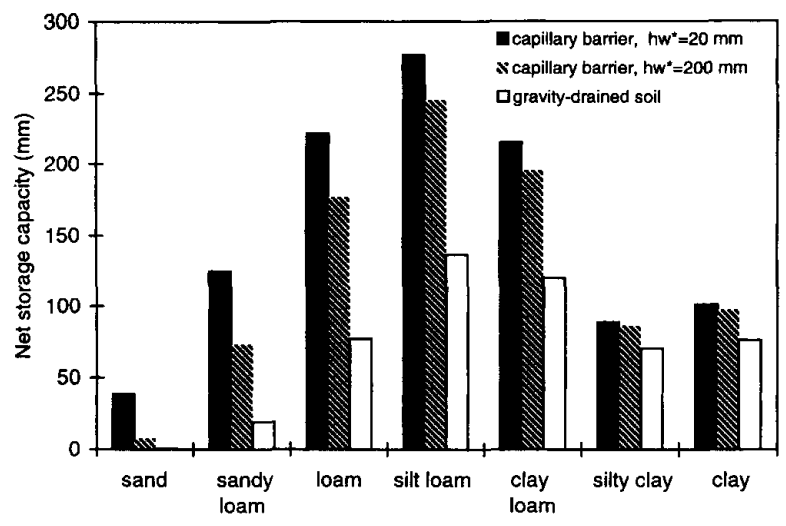

FIG. 5. Net Storage Capacity of Capillary Barriers and Simple Soll Layers Using Soils of Various Textures: Thickness of Soil Layers Assumed to Be $1 \mathrm{~m}$

TABLE 1. Parameters for Various Soil Textures [Data from Carsel and Parrish (1988)]

\begin{tabular}{l|c|c|c|c}
\hline $\begin{array}{c}\text { Soil } \\
\text { texture } \\
(1)\end{array}$ & $\begin{array}{c}\boldsymbol{\theta}_{r} \\
(2)\end{array}$ & $\begin{array}{c}\theta_{s} \\
(3)\end{array}$ & $\begin{array}{c}\alpha \\
\left(\mathrm{mm}^{-1}\right) \\
(4)\end{array}$ & $\begin{array}{c}n \\
(5)\end{array}$ \\
\hline Sand & 0.045 & 0.43 & 0.0145 & 2.68 \\
Sandy loam & 0.065 & 0.41 & 0.0075 & 1.89 \\
Loam & 0.078 & 0.43 & 0.0036 & 1.56 \\
Silt loam & 0.067 & 0.45 & 0.0020 & 1.41 \\
Clay loam & 0.095 & 0.41 & 0.0019 & 1.31 \\
Silty clay & 0.070 & 0.36 & 0.0005 & 1.09 \\
Clay & 0.068 & 0.38 & 0.0008 & 1.09 \\
\hline \hline
\end{tabular}

is also calculated assuming a water entry head of the coarse layer of $200 \mathrm{~mm}$ for comparison, which may be appropriate for a coarse sand. The water storage capacity of a 1-m-thick simple soil layer is calculated from (1), with the field capacity estimated as the water content at $3,500 \mathrm{~mm}$ of suction head from (9). The net storage capacity is determined by subtracting the PWP, calculated from (9) at $150 \mathrm{~m}$ of suction head, from the calculated storage capacity. The van Genuchten parameters used for the different soil textures are given in Table 1.

It is important to recognize the approximate nature of the estimate of storage capacity based on the field capacity concept. The common definition of field capacity used here is arbitrary, and ignores other factors that affect the amount of water retained in a soil layer [e.g., Jury et al. (1991); Cassel and Nielsen (1986)]. For example, the calculation of storage capacity of a soil layer with (1) neglects the properties of the underlying soils on the amount of water retained in a soil layer. However, the field capacity concept is widely used because it fills the need for a simple parameter that defines the storage capacity of a soil layer, including the design of soil covers over waste sites [e.g., Anderson et al. (1993)]. In this paper, field capacity is used for comparative purposes to provide a first-order estimate of the water storage capacity of a soil layer independent of the underlying waste or foundation soil properties.

The results presented in Fig. 5 illustrate that the benefit of a capillary barrier compared to a simple soil cover depends on the texture of the overlying soil. Soils that include loam in their classification tend to benefit the most from the capillary break. In contrast, fine-grained soils with a large field capacity, such as clays, achieve much less of a storage increase from the underlying capillary break. The storage capacity of the sand is increased by the capillary barrier, but to a relatively small value. When the water entry head of the coarse layer is increased to $200 \mathrm{~mm}$, the net storage capacity of the capillary barrier decreases for all soil textures. The magnitude of the relative reduction in the net storage capacity increases for soils with a coarser texture, e.g., sands.

There is a limit to the additional storage capacity achieved by increasing the thickness of the overlying soil. In Fig. 6 , the increase in water storage capacity at breakthrough due to an underlying capillary break (the storage capacity of a soil with a capillary break minus the storage capacity without a capillary break) is given as a function of the soil layer thickness for soils of various texture. Most of the additional storage in a sand layer from an underlying capillary break occurs close to the fine-coarse interface. Consequently, there is little additional storage gained from thick sand layers. Both the sandy loam and the silt loam derive increasing water storage capacity up to about a $2 \mathrm{~m}$ soil layer thickness, indicating the additional water stored in a capillary barrier configuration extends much farther above the interface than for the case when sand is used.

A plot of the moisture characteristic function for the overlying soil can be used to provide insight into the expected water storage within a capillary barrier. Consider the moisture characteristic curves given by Figs. 7 and 8 for a sandy loam and a clay loam, respectively, placed over a coarse layer and thus forming a capillary barrier. Because the suction head at any depth above the interface at breakthrough can be approximated from $h=z+h_{w}^{*}$ (the unit slope profile), the water

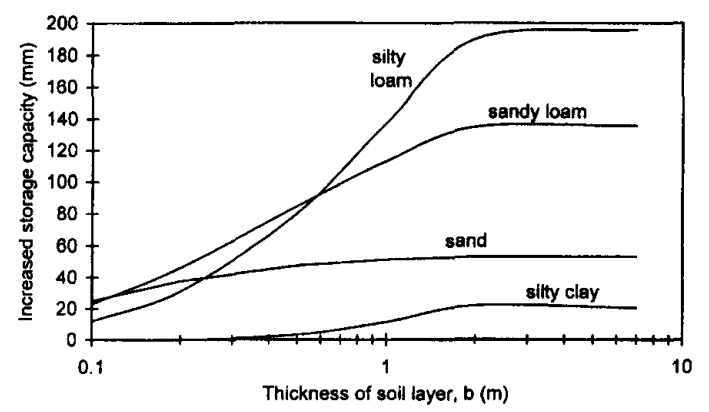

FIG. 6. Additional Storage Capacity Afforded by Capillary Barrier as Function of Thickness of Soil Layer for Four Soll Textures

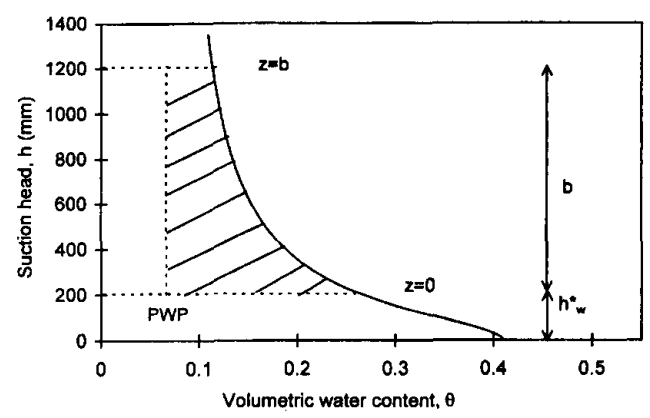

FIG. 7. Moisture Characteristic Curve for Sandy Loam

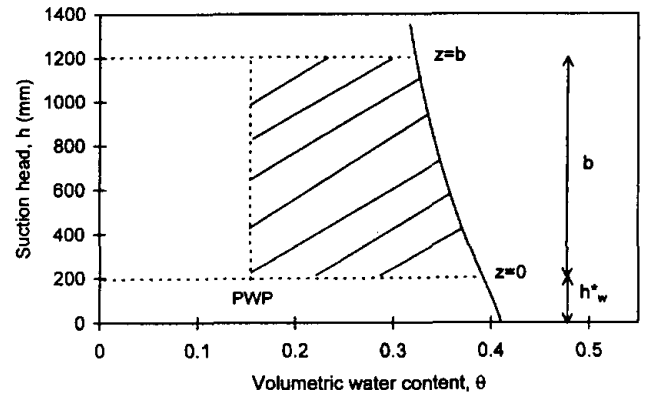

FIG. 8. Moisture Characteristic Curve for Clay Loam 
content as a function of depth can be determined from the moisture characteristic function. In the figures, the suction heads at the interface $\left(h=h_{w}^{*}\right.$ at $\left.z=0\right)$ and at the top of the layer $\left(h=b+h_{w}^{*}\right.$ at $\left.z=b\right)$ are shown for the case $h_{w}^{*}=200$ $\mathrm{mm}$ and $b=1 \mathrm{~m}$. The area defined by the moisture characteristic curve and bounded by these suction heads is the storage capacity of the capillary barrier. The net storage capacity can be determined by including on the figure a lower bound of the removable water content such as the permanent wilting point.

Inspecting moisture characteristic curves lends visual confirmation of the previous discussion of factors that influence the storage capacity of capillary barriers. Differences in texture are reflected in the shape of the moisture characteristic curve, as illustrated by the differences between the moisture characteristic curves for the coarser-textured sandy loam (Fig. 7) and the finer-textured clay loam (Fig. 8). The moisture characteristic curves of fine-grained soils tend to be steep, indicating that their storage will be great and they will be relatively insensitive to the value of $h_{w}^{*}$. However, the additional storage provided by the capillary barrier compared to a simple soil layer may not be significant because fine-grained soils often have large FC values. Further, the net storage capacity of these soils in either a capillary barrier or simple soil configuration will be limited if they also have a large PWP. Coarser-grained soils usually experience a substantial change in water content at low suction heads, as is the case for the sandy loam. A capillary barrier comprised of a sandy loam soil will achieve much of its additional storage near the interface; thus its storage capacity will be relatively sensitive to the value of $h_{w}^{*}$.

The results presented in Figs. 5 and 6 are conservative with respect to the benefit of a capillary barrier compared to a simple soil cover. First, the water storage capacity of the simple soil layer [calculated from (1)] is probably overestimated because it is predicated on the assumption that there is no downward water movement at water contents below the field capacity. In fact, most gravity-drained soil layers will drain to water contents below their FC (Stephens 1995). Consequently, the storage within simple soil layers would be reduced over that calculated by (1), and the relative benefit of a capillary barrier would be correspondingly increased. Second, the assumption of the unit slope suction head profile within the overlying soil layer is conservative with respect to the storage capacity of the capillary barrier. The numerical simulations indicate that a suction head profile somewhat steeper than the unit slope profile develops at breakthrough. The steeper suction head profile means more water is stored in the capillary barrier than that estimated using the unit slope assumption. The additional storage may be modest; for the suction head profiles that deviated the most from the unit slope profile in Fig. 4, the storage capacity was only $7 \%$ more than that estimated assuming a unit slope profile.

The parameters in Table 1 were derived from tests in which the soil was progressively dried (Carsel and Parrish 1988). The soil in a capillary barrier configuration approaching breakthrough may, on balance, be expected to experience wetting behavior, although its actual behavior will likely be some complicated combination of wetting and drying. Due to hysteresis, at the same value of suction head, a soil will contain less water if it is being wetted compared to one being dried. Thus, the use of wetting parameters will provide a lower, more conservative estimate of storage capacity.

\section{CONCLUSIONS}

This paper presents a method to estimate the storage capacity of capillary barriers. The method assumes that a unit slope suction head profile develops in the overlying soil at breakthrough, that is, $h=z+h_{w}^{*}$. The corresponding water content in the soil can be found from the moisture characteristic curve. The total water storage capacity is found by integrating the water content over the depth of the overlying soil layer.

Application of this method reveals the influence of the texture of the overlying soil layer on the expected water storage capacity of a capillary barrier. For the material properties used in this study, soils broadly classified as loams derive the most benefit in a capillary barrier configuration. Coarse sands and fine-grained clays are expected to achieve much less additional storage capacity from an underlying capillary break. In addition to the properties of the overlying soil layer, the method for estimating the storage capacity includes the influence of the water entry head of the underlying soil.

The method presented in this paper can be used to obtain conservative storage capacity estimates without the need for numerical simulations. The benefit of including a capillary break beneath a soil layer can be estimated for a particular soil. The impact of design variations such as the thickness of the overlying fine soil layer or the properties of the coarse layer can be readily determined.

\section{APPENDIX I. NUMERICAL SIMULATIONS OF SUCTION HEADS WITHIN CAPILLARY BARRIER SYSTEM}

The capillary barrier systems were simulated using a twostep procedure. First, the HELP program was used to obtain site and design specific flux variables termed Infiltration (I) and Evapotranspiration (ET). The HELP program (Schroeder et al. 1994) combines transient, daily potential infiltration, which it generates from climatic data, with cover design-dependent runoff and ET data to generate the two fluxes of interest. These terms were used as sources and sinks in TRACR3D (Travis and Birdsell 1991), a code capable of solving transient two-phase flow in the second step of the procedure. Infiltration is a surface flux, whereas ET removes water within the soil as a function of depth consistent with the HELP methodology. TRACR3D has been demonstrated to satisfactorily simulate unsaturated water movement associated with capillary barriers, including reasonably reproducing the field tests of capillary barriers (Morris and Stormont 1997b). A complete description of the numerical procedures is given in Morris and Stormont (1997a).

The capillary barrier cover consisted of $0.66 \mathrm{~m}$ of a silty soil overlying a gravel coarse layer. The van Genuchten parameters for these soils are given in Table 2 . The HELP code allows input of evaporative depth, runoff coefficient, leaf area index (LAI), and vegetation amount in addition to the actual cover design and climatic data. Values for these inputs were $0.6 \mathrm{~m}$ for the evaporative depth, 0.82 for the runoff coefficient, 2 for the LAI, and "fair" vegetation cover. The TRACR3D code was run using the default options for most parameters, with no changes made between designs. Boundary conditions were no flow with the exception of the bottom boundary, which was set to maintain atmospheric conditions, an option in TRACR3D. Additionally, both the HELP and TRACR3D models were run using an initial soil saturation determined by HELP based on the first year of simulation.

All simulations were conducted for 10 years using the climate of Chicago so that the cumulative effects of precipitation

TABLE 2. Parameters for Solls Used in Numerical Simulations

\begin{tabular}{l|c|c|c|c|c}
\hline \hline $\begin{array}{c}\text { Soil texture } \\
(1)\end{array}$ & $\begin{array}{c}K_{s} \\
(\mathrm{~mm} / \mathrm{sec}) \\
(2)\end{array}$ & $\begin{array}{c}\theta_{r} \\
(3)\end{array}$ & $\begin{array}{c}\theta_{s} \\
(4)\end{array}$ & $\begin{array}{c}\alpha \\
\left(\mathrm{mm}^{-1}\right) \\
(5)\end{array}$ & $\begin{array}{c}n \\
(6)\end{array}$ \\
\hline Silty sand (high $K)$ & $1.4 \times 10^{-2}$ & 0.077 & 0.442 & 0.0015 & 2.03 \\
Silty sand (low $K)$ & $1.4 \times 10^{-3}$ & 0.077 & 0.442 & 0.0015 & 2.03 \\
Gravel & $1.0 \times 10^{2}$ & 0.005 & 0.42 & 0.493 & 2.19 \\
\hline \hline
\end{tabular}


and evapotranspiration would be experienced by the capillary barrier. This multiyear time period is extremely important for the typical capillary barrier system because the major moisture removal process is ET. If ET is lower than infiltration in a particular period of time, the overlying fine soil layer may accumulate moisture over time, leading to a large breakthrough event. A 10-year period that contained the five-year period with the highest cumulative precipitation was chosen from the 100-year record available.

\section{ACKNOWLEDGMENT}

The partial support of Sandia National Laboratories, Albuquerque, N.M., for this study is gratefully acknowledged.

\section{APPENDIX II. REFERENCES}

Anderson, J. E., Nowak, R. S., Ratzlaff, T. D., and Markham, O. D. (1993). "Managing soil moisture on waste burials sites in arid regions." J. Envir. Quality, 22, 62-69.

Baker, R. S., and Hillel, D. (1990). "Laboratory tests of a theory of fingering during infiltration into layered soils." Soil Sci. Soc. Am. J., $54,20-30$.

Brooks, R., and Corey, A. (1964). "Hydraulic properties of porous media." Hydrology Paper 3, Colorado State University, Fort Collins, Colo.

Carsel, R. F., and Parrish, R. S. (1988). "Developing joint probability distributions of soil water retention characteristics." Water Resour. Res., 24(5), 755-769.

Cassel, D. K., and Nielsen, D. R. (1986). "Field capacity and available water capacity." Methods of soil analysis, part 1. Physical and mineralogical methods, Agronomy Monograph No. 9, 2nd Ed., Soil Science Society of America, Madison, Wis

Gee, G. W., Wierenga, P. J., Andraski, B. J., Young, M. H., Fayer, M. J., and Rockhold, M. L. (1994). "Variations in water balance and recharge potential at three Western Desert sites." Soil Sci. Soc. Am. J., 58, 6372.

Hakonson, T. E., Lane, L. J., Nyhan, J. W., Barnes, F. J., and DePoorter, G. L. (1989). "Trench-cover systems for manipulating water balance on low-level radioactive-waste repository sites." U.S. Geological Circular 1036, 73-80.

Johnson, T. M., Cartwright, K., Herzog, B. L., and Larson, T. H. (1983). "Modeling of moisture movement through layered trench covers." Role of the unsaturated zone in radioactive and hazardous waste disposal, J. W. Mercer, P. S. C. Rao, and I. W. Marine, eds., Ann Arbor Science, Ann Arbor, Mich., 11-26.

Jury, W. A., Gardner, W. R., and Gardner, W. H. (1991). Soil physics. 5th Ed., John Wiley \& Sons, Inc., New York, N.Y.

Morris, C. E., and Stormont, J. C. (1997a). "Capillary barriers and subtitle D covers: estimating equivalency." J. Envir. Engrg., ASCE, $123(1), 3-10$
Morris, C. E., and Stormont, J. C. (1997b). "Numerical simulations of capillary barrier field tests." Proc., 1997 Int. Containment Technol. Conf., St. Petersburg, Fla., 275-281.

Schroeder, P. R., Aziz, N. M., Lloyd, C. M., and Zappi, P. A. (1994) "The Hydrologic Evaluation of Landfill Performance (HELP) model: user's guide for version 3." EPA/600/9-94/xxxx, U.S. Environmenta Protection Agency Risk Reduction Engineering Laboratory, Cincinnati, Ohio.

Stephens, D. B. (1995). Vadose zone hydrology. CRC Press, Boca Raton, Fla.

Stormont, J. C. (1997). "Incorporating capillary barriers in surface cover systems." Conf. Proc. of Landfill Capping in the Semi-Arid West: Problems, Perspectives, and Solutions, T. D. Reynolds and R. C. Morris, eds., Environmental Science and Research Foundation, Idaho Falls, Idaho, 39-51.

Travis, B. J., and Birdsell, K. H. (1991). "TRACR3D: a model of flow and transport in porous media." $L A-11798-M(U C-814)$, Los Alamos National Laboratories, Los Alamos, N.M.

van Genuchten, M. T. (1980). "A closed-form equation for predicting the hydraulic conductivity of unsaturated soils." Soil Sci. Soc. Am. J., 44, 892-898.

\section{APPENDIX III. NOTATION}

The following symbols are used in this paper:

$b=$ thickness of soil layer;

$\mathrm{FC}=$ field capacity;

$H=$ total head;

$h=$ suction head;

$h_{q}=$ suction head in response to constant infiltration;

$h_{w}^{*}=$ water entry suction head;

$K=$ hydraulic conductivity;

$K\left(h_{q}\right)=$ hydraulic conductivity at suction head $h_{q}$;

$K\left(b+h_{w}^{*}\right)=$ hydraulic conductivity at suction head $\left(b+h_{w}^{*}\right)$;

$K_{s}=$ saturated hydraulic conductivity;

$m=$ van Genuchten function parameter;

NSC $=$ net storage capacity;

$n=$ van Genuchten function parameter;

PWP = permanent wilting point;

$\mathrm{SC}=$ storage capacity;

$q=$ infiltration rate or flux;

$q_{c}=$ critical flux;

$z$ = distance above bottom of soil layer;

$\alpha=$ van Genuchten function parameter;

$\boldsymbol{\theta}=$ volumetric water content;

$\theta(h)=$ volumetric water content at suction head $h$;

$\theta_{r}=$ residual volumetric water content; and

$\theta_{s}=$ saturated volumetric water content. 